\title{
An index to evaluate the quality of taxonomic publications
}

\author{
ANTONIO G. VALDECASAS \\ Museo Nacional Ciencias Naturales, CSIC. c/José Gutiérrez Abascal, 2. 28006-Madrid, Spain. E-mail: valdeca@gmail.com
}

\begin{abstract}
"Not everything that counts is countable, and not everything that's countable counts." A. Einstein (Bornmann and Daniel 2009)

"It is a fact that taxonomic monographs are rarely read by general biologists; in fact,many of them are read by only a few specialists." (Mayr, Linsley \& Usinger 1953)
\end{abstract}

The number of citations is not an adequate measure of taxonomic quality, which is a view that is shared with other scientific disciplines (Seglen1997; Valdecasas et al. 2000; Walter et al. 2003). A recent editorial in Nature claims that “... citations are an unreliable measure of importance" (Anon. 2010: 850) and uses two chemistry papers as an example. The first paper was cited 182 times in the same period that the other paper was cited only 13 times. However, the latter paper is recognized as 'outstanding' by the experts from the American Chemical Society, which would not be revealed by the arbitrary counting of citations. Similar examples have evoked critical editorial comments in high-impact journals. In the context of a possible future use of the Impact Factor (IF), the editor of EMBO Reports states:

"[The] Impact Factor, which began as an attempt to identify and recognize the academic quality of scientific work, is already a commercial indicator in many ways on a par with the Global Dow Jones Index... Someone should perhaps have done something 40 years ago to arrest the trend towards judging the value of scientific work by a self-inflating and, to a large extent, arbitrary number; we all know that a scientific finding's true value to humanity can only be judged by history. "(Jacobs 2009: 1067).

Mark Patterson, the Director of Publishing at PLoS, agrees with Jacobs' assessment:

"But what is to be done when the journal impact factor is so tightly woven into the fabric of research assessment? How could we escape Jacobs's nightmare scenario? At PLoS, we believe articles should be judged on their own merits, rather than on the basis of the journal in which they happen to be published" (Patterson 2009a: 1186).

What is striking here is how Patterson's and Jacobs' comments parallel Van Valen's motto, "The primacy of content over display".

\section{Citations, IF and Taxonomy}

With the objective of addressing the 'quality of science', the first proposal to use citation indexes for science was published by Garfield (1955): "...I propose a bibliographic system for science literature that can eliminate the uncritical citation of fraudulent, incomplete, or obsolete data..." The use of journal citations in articles to specifically select those with a higher number of citations to add to a library was initiated by Gross \& Gross in 1927 (Archambault \& Larivière 2009). Archambault and Lariviere tracked the genesis of the practice of using citations as selection criteria to produce lists of 'relevant journals', along with the successive incarnations and refinements of journal 'selection' procedures. This practice continued until Martyn \& Gilchrist (1968) and then Garfield (1972) established the IF as it is currently known (in Archambault \& Larivière, 2009). Relevance and quality are considered strongly correlated terms by Garfield (2003) and others. Recently, Krell (2010) introduced the term 'attention' as an interpretation of what a citation really means. However, he is currently alone in assigning this particular meaning to the IF.

Valdecasas et al. (2000) suggested that the "reliance on citation index was detrimental to taxonomy". Our basic argument in that article was that the citation and journal impact factor were being used by managers and funding 
agencies as criteria to promote and finance research. Because taxonomy is a discipline that is not highly cited, the professionals of taxonomy are not very competitive on the basis of these criteria. This statement has been confirmed by the recent trends in academia (Meier \& Lim, 2009, page: 93).Subsequently, Krell (2000) proposed that IF are not relevant to taxonomy (and we agree with him). Garfield (2000) answered Krell (2000) and stated that "[t]axonomy is small, but it has its citation classics", meaning that there were taxonomic papers with a substantial number of citations. However, Garfield's comments do not consider taxonomic papers that have not been cited despite their valuable contributions to the field. In his reply, Garfield only mentioned Robert R. Sokal and Edward O. Wilson as two representative taxonomic authors with citation classics. On one hand, Sokal never wrote a proper taxonomic paper, i.e., a paper that discovered, described or revised a taxon. Sokal is a mathematical methodologist, who occasionally worked with taxonomists (e.g., the bee specialist Charles D. Michener). E. O. Wilson has citation classics, but they are not his publications on taxonomy. The following are the publications by Wilson that are considered citation classics (none of them are strictly taxonomic papers; http://garfield.library.upenn.edu/classics/classics_s.html, accessed 23 May 2011):

- Brown, W. L. and E. 0. Wilson. 1956. Character displacement. Systematic Zoology, 5: 49-64.

- MacArthur, R. H. and E. 0. Wilson. 1967. The Theory of Island Biogeography. Princeton Univ. Press, Princeton, NJ. 203 pp.

- Simberloff, D. S. and E. 0. Wilson. 1969. Experimental zoogeography of islands: the colonization of empty islands. Ecology, 50(2): 278-296.

- Wilson, E. 0. 1971. The Insect Societies. Belknap Press of Harvard Univ. Press, Cambridge, MA. 548 pp.

- Wilson, E. 0. 1975. Sociobiology: The New Synthesis. Belknap Press of Harvard Univ. Press, Cambridge, MA. 697 pp.

E.O. Wilson has more than 370 publications (see his $\mathrm{CV}$ at http://www.discoverlife.org/who/CV/ Wilson,_Edward.html, accessed 23 May 2011). In total, 231 publications were covered by the Zoological Record (ZR), and 260 publications were covered by the Web of Knowledge (WOK) database, which maintains a record of the number of citations a given paper has received. Of his taxonomic papers (i.e., papers with descriptions of species; near 40 publications) four are included in the WOK database. These taxonomic papers in the WOK database have 22 citations in total. His last description of an ant species in Colombia (Fernandez \& Wilson 2008; included in the WOK database), which was performed in 2008, has zero citations, and it is not expected to obtain more in the near future. There is no reason to believe that Wilson has not invested the same high quality effort in this publication as he has in any of his other publications. Wilson has a publication in Biotropica on tree ants that has 102 citations. However, the work is a list of species, which have been identified to genus or are potentially new species, without any descriptions or taxonomic notes. Finally, Wilson's important paper on Mesozoic ants (Wilson et al. 1967a) that was published in the journal Psyche is not included in the WOK database. However, its simultaneous brief note in Science (Wilson et al.1967b) received 33 citations (the interesting facts that are related to taxonomy are located in the publication in Psyche, to which the publication in Science refers for further information). We maintain, on the basis of our personal experience, that managers and funding agencies rely on citations and the IF to provide financing and to make decisions about promotions. We now have a plethora of indexes that are based on citations, which are taken as correlates of academic quality. Moreover, the open portal 'Publish or Perish' (http://www.harzing.com, accessed 23 May 2011) calculates, at no cost (using the Google Scholar database), a set of indexes that are based on the citations of any science or humanities researcher. The Scimago portal (http://www.scimagojr.com/) provides an alternative journal rank to that of Thomson and Reuters (IF owners). The increase in the number of available indexes suggests the popularity of 'citation' metrics with the educated public.

\section{Finding a way out}

There are plausible solutions to Jacobs' 'nightmare scenario'. Some journals are studying different methods to evaluate the importance of published scientific papers. The PLoS organization has its own 'article-level metrics program' that is based on 'usage data' and is open to external contributions to improve the program (Patterson 2009b). Walter et al. (2003) proposed a method based on content for medical specialties. In taxonomy, criteria such as the number of citations or usage data will not highlight the quality of a published paper or monograph. The current citation metrics do not reflect the quality of taxonomic work because the breadth of the subject matter is limited (i.e., single taxa) and taxonomists usually work in small cliques (Ebach et al. 2011). To find a viable citation metric for taxonomy, there is a temptation to develop an 'integrative' or 'holistic' taxonomic index, i.e., one that values the quality of a taxonomic paper on the basis of the data and the range of techniques used, regardless of their diagnostic relevance, or the use of several types of output, such as images or DNA (see Page 2009). In this case, taxonomists with vast morphological or DNA datasets and accompanying SEM micrographs would fare better than single diagnostic works. This metric would favor a taxonomist 
from a well-funded and well-staffed lab with access to infrastructure and technology over a single museum taxonomist who is armed with only an old Zeiss microscope and a drawing tube.A fair metric should award good taxonomy over technology - the 'primacy of content over display'. Although a fair metric may appear to be biased against the recent bioinformatics boom, we propose that it should not be construed as such. Bioinformatics has its place, as does highquality taxonomy. Whether we use pen and paper or relational databases should not matter. The IF is clearly unfair to taxonomists, who primarily publish in journals with low impact factors or in journals that do not have an IF (because they are not covered by the WOK database). A new honest and transparent method is required that reflects the importance and relevance of taxonomic descriptions and systematic revisions. The following suggestions are intended as starting points from which the taxonomic and scientific community at large can create a new, fair and valid metric that assesses the taxonomic quality of published works.

\section{The T-index: Proposing a New Citation Metric}

I propose the following tentative Taxonomy Index (herein T-Index) as a standard metric to assess the taxonomic quality of a published taxonomic work. The T-index is based on the following criteria:

1. The description and diagnosis are in accordance with the relevant code of nomenclature.

2. The standard of description is adequate to contemporary practice in the corresponding clade.

3. The journal has unbiased editor and referee systems.

4. Any molecular or morphometric evidence (i.e., molecular tree) that supports a new classification is accompanied by a written description and a diagnosis that is in accordance to the relevant code of nomenclature.

5. New taxa hypotheses and full revision work are accorded similar merit.

6. Taxa diversity 'context' (see below) affects the weight assigned to criterion (5).

The discovery of a new taxon is made in the context of another related taxon. For instance, new species are diagnosed within a species complex or a genus, following the various codes of nomenclature. At least in eukaryotes, a good taxonomic paper should provide enough data to diagnose a new taxon within a taxon on the basis of their morphological characteristics. However, any additional information, including cytogenetic, behavior or DNA phenotype, is welcome. A single species description that is based solely on the species diagnostic characteristics but is lacking a comparison to other members of its group is of low taxonomic value (i.e., the diagnosis may be synonymous with another described species). Another example includes a situation where five new species are described in a monographic revision of a genus consisting of 100 known species or a work consisting of a genus with 20 known species. The former work requires a far greater scope and knowledge than the latter. The T-index does not necessarily apply only to those discovering new taxa. Taxonomic revisions may uncover new discoveries and classifications, which are developed by new data or a new insight into the relationships between taxa (e.g., cladograms). Full taxon revisions, such as new taxon descriptions, will be assessed equally under the T-index. In this sense, any nomenclatural act except those that are based on misprints or any other trivial error will be considered. For instance, the genus Arrenurus (Acari, Hydrachnidia) has more than 400 described species (Viets 1987) within several subgenera and 'species groups'. If a publication revises or describes a certain number of species in one of the subgenera, e.g., Truncaturus, the work will be evaluated in relation to the number of species that are already described in this subgenus. Any new or revised taxon description will be evaluated in relation to the number of taxa in its current clade, i.e., the new genus in the family clade and the new species in the genus clade.

\section{How the T-Index works}

The T-Index is measured by including only the following two variables: $\mathbf{N}_{\mathrm{i}}$, which is the number of new taxa discovered or revised in the clade that is being studied with rank $\mathbf{i}$ (e.g., order, family, etc.), and $\mathbf{S}_{\mathbf{i}}$, which is the number of taxa in that clade and rank after the study. The second variable is used to calculate a weighting factor that qualifies the effort of the taxon that is discovered or treated in the publication in relation to all known taxa in the clade.

$$
T=\sum \frac{N_{i}^{2}}{S_{i}}
$$


For instance, if the study includes taxa of rank order, family, genus and species, the index would include a term for each of them:

$T=N_{o} \frac{N_{o}}{S_{o}}+N_{f} \frac{N_{f}}{S_{f}}+N_{g} \frac{N_{g}}{S_{g}}+N_{s} \frac{N_{s}}{S_{s}}$

As a reference work, Table 1 tabulates the number of taxa that were treated in Darwin's four volumes on extant and fossil Cirripedia (the figures in Table 1 are close approximations of the total number of the nomenclatural acts by Darwin in 1851 and 1854 works).

$\mathrm{T}_{\mathrm{vol} \_1}=178.5 ; \mathrm{T}_{\mathrm{vol} \_2}=82.5 ; \mathrm{T}_{\mathrm{vol} \_3}=347 ; \mathrm{T}_{\mathrm{vol} \_4}=85$

Monographies and revision works, such as Darwin's monograph on the Cirripedia, usually get high values when compared with single or few species description works, which seems reasonable if we take into account the amount of effort and time necessary to perform them (eight years in the case of Darwin's Cirripedia).

Table 2 tabulates the number of new species that were found or revised in an imaginary work on the clade Hydrachnidia. In this case, the value of the index is very small:

$T=\frac{1}{248}+\frac{4}{126}+\frac{9}{183}=0.08$

The T-Index increases as the number of taxa that are studied or revised reaches the number that is already known. In this example, the imaginary authors studied $0.4 \%$ of the species of the known Atractides (Atractides), $1.6 \%$ of the species of Monatractides and $1.6 \%$ of the species of Torrenticola (no subgenus specified).

TABLE 1. Taxa treated in Darwin's four volumes on recent and fossil Cirripedia.

\begin{tabular}{lllll}
\hline Taxa & Order & Family & Genera & Species \\
\hline $\begin{array}{l}\text { Darwin Cirripedia Vol. 1 F. } \\
\text { Lepadidae }\end{array}$ & $1 / 3$ & $1 / 5$ & $40 / 40$ & $138 / 138$ \\
$\begin{array}{l}\text { Darwin Cirripedia Vol. 2 Fossil } \\
\text { Lepadidae }\end{array}$ & $1 / 3$ & $1 / 5$ & $12 / 12$ & $70 / 70$ \\
$\begin{array}{l}\text { Darwin Cirripedia Vol. 3 F. } \\
\text { Balanidae; F. Verrucidae }\end{array}$ & $3 / 3$ & $3 / 3$ & $41 / 41$ & $304 / 304$ \\
$\begin{array}{l}\text { Darwin Cirripedia Vol. 4 Fossil F. } \\
\text { Balanidae and F. Verrucidae }\end{array}$ & - & $3 / 3$ & $24 / 24$ & $60 / 60$ \\
\hline
\end{tabular}

TABLE 2. Species treated in an imaginary work in the clade Hydrachnidia (Acari, Parasitengona).

\begin{tabular}{llll}
\hline Taxa & New and revised & Previously known & Total \\
\hline Atractides & 1 & 247 & 248 \\
Monatractides & 2 & 124 & 126 \\
Torrenticola & 3 & 180 & 183 \\
\hline
\end{tabular}

\section{The T-Index in the world of academia}

One may argue that evaluating taxonomic publications is difficult to implement automatically. We propose that the evaluation of taxonomic publications is not necessarily difficult. For example, the Zoological Record database (which maintains a registry of all zoological literature that is relevant for biodiversity studies) distinguishes between new species, new rediagnoses and new records under their 'systematic data' field entry. In this case, it would be feasible to automatically extract the number of new taxa and the number of rewritten descriptions that are required to calculate the value of the work under examination.In addition, several sites are available on the internet to extract the number of species that are already known within a specific taxon. In this example, we used an open access data list for Acari (http:/ /insects.tamu.edu/research/collection/hallan/Acari/Family/Actinedida1.htm; accessed 24 May 2011). However, similar 
lists for all types of organisms may be found, such as the Catalogue of Life (http://www.catalogueoflife.org/), which at the time of this writing had not yet completed the Acari record.The proposed index is radically different from those that have been previously suggested, because the IF or the H-index are based on number of citations and the T-Index is based on content. It may be argued that some 'bad' taxonomist may publish poor-quality papers. The T-index, like any metric, only gives us an indication of what is assumed to be of high quality based on the filters of the journal editors and the peer review process, which are responsible for assessing whether a manuscript fits the standard of its time. As the sociologist of science, Derek J. De la Solla Price, made explicit some time ago (De la Solla Price 1969), the publication behavior of science and technology are different. Academia is clearly papyrocentric, and industry is plainly papyrofobic ${ }^{1}$. The basic surrogate criteria used to value the merit of scientific work are derived from the public creation of science and are based on the number of citations and the IF. However, as argued above, the number of citations is a poor indication of scientific merit. Let us keep the honorable academic open-publishing tradition and value content rather than any other surrogate variable. The proposed index could be used alongside previous indices that are based on the number of citations. This combined approach would make it possible to gauge the resonance of a particular work in the scientific community without losing sight of its quality. We hope that this proposal will create a forum for debate about defining a new metric to assess the quality of taxonomic papers. The Science Citation Index does not adequately consider taxonomists and taxonomy. Any metric that works in the interest of taxonomists would present a better and fairer standard.

\section{Acknowledgements}

I thank Malte C. Ebach for encouraging this contribution to Zootaxa and for his editorial input. Roderic D. M. Page and Frank-Thorsten Krell raised a number of points that improved the clarity of this contribution. I dedicate this work to the Evaluation Committee that rejected my promotion (sexenio), assigning a value of 2 (max. 10) to the book 'Contribution to Morphometrics' that I coauthored and edited with the statement "Diffusion through insufficient impact". The book, which has nearly 400 citations in a field with a mean number of 8.5 citations per article, is the best example of the illusory effect that citations can have on a scientific career. American Journal Experts corrected a previous draft of this ms. This work was partially supported by grant CGL2009- 08943 from the Ministerio de Ciencia e Innovación.

\section{References}

Anon (2010) Nature's choices. Nature, 463, 850.

Agrawal, A.A. (2005) Corruption of journal Impact Factors. Trends in Ecology and Evolution, 20, 157.

Archambault, É. \& Larivière, V. (2009) History of the journal impact factor: Contingencies and consequences. Scientometrics, 79, 635-649.

Bornmmann, L. \& Daniel, H.D. (2009) The state of h index research. Embo reports, 10, 2- 6.

Darwin, C. (1851) A Monograph of the Sub-class Cirripedia, with Figures of all the Species. The Lepadidae; or, Pedunculated Cirripedes. (Available at http://www.biodiversitylibrary.org/ Accessed 24 May 2011)

Darwin, C. (1851) A Monograph on the Fossil Lepadidae, or, Pedunculated Cirripedes of Great Britain. (Available at http:// www.biodiversitylibrary.org/ Accessed 24 May 2011)

Darwin, C. (1854) A Monograph of the Sub-class Cirripedia, with Figures of all the Species. The Balanidae (or Sessile Cirripedes); the Verrucidae, etc. (Available at http://www.biodiversitylibrary.org/ Accessed 24 May 2011)

Darwin, C. (1854) A Monograph on the Fossil Balanidae and Verrucidae of Great Britain. (Available at http:// www.biodiversitylibrary.org/ Accessed 24 May 2011)

De Solla Price, D.J. (1969) The Structure of Publication in Science and Technology. In: Gruber, W.H., Marquis, D.G. (Eds.), Factors in the Transfer of Technology, MIT Press, Cambridge, MA, pp. 91-104.

Ebach, M., Valdecasas, A.G. \& Wheeler, Q.D. (2011) Impediments to taxonomy and users of taxonomy: Accessibility and Impact Evaluation. Cladistics 27 no. doi: 10.1111/j.1096-0031.2011.00348.x

Jacobs, H. (2009) Editorial. Pay to cite. EMBO Reports, 10, 1067.

Fernandez, F. \& Wilson, E.O. (2008) Jose Celestino Mutis, the ants, and Pheidole mutisi sp. nov. Revista Colombiana de Entomologia, 34, 203-208.

Garfield, E. (1955) Citation indexes for science. Science, 122, 468-471.

Garfield, E. (2000) Taxonomy is small, but it has its citation classics. Nature, 413, 107.

Garfield, E. (2003) The meaning of the Impact Factor. International Journal of Clinical and Health Psychology, 3, 363-369.

1. De la Solla Price (1974) discussing the place of publications in science and technology says:"the scientist ...is heavily motivated to publish - this is the key to all the inner springs of his drive to do science. In technology it is otherwise; the tradition crudely speaking is to conceal in order to have a new product or a process before other". 
Krell, F.T. (2000) Impact factors aren't relevant to taxonomy. Nature, 405, 507-508.

Krell, F.T. (2010) Should editors influence journal impact factors? Learned Publishing, 23, 59-62.

Mayr, E., Linsley, E.G. \& Usinger, R.L. (1953) Methods and Principles of Systematic Zoology. McGraw-Hill, New York, pp. 328.

Meier, R. \& Lim, G.S. (2009) Conflict, convergent evolution, and the relative importance of immature and adult characters in Endopterygote Phylogenetics. Annual review of Entomology, 54, 85-104.

Page, R. (2009) Is taxonomy disadvantaged by standard measures of academic performance? In: http://network.nature.com/ groups/taxonomy/forum/topics/3983, accessed 24 May 2011.

Patterson, M. (2009a) Is the end in cite? EMBO Reports, 10, 1186.

Patterson, M. (2009b) Article-level metrics at PLoS - addition of usage data. Available at: http://blogs.plos.org/plos/2009/09/ article-level-metrics-at-plos-addition-of-usage-data/ Accessed 24 May 2011.

Seglen, P.O. (1997) Citations and journal impact factors: questionable indicators of research quality. Allergy, 52, $1050-1056$.

Thomaz, S.M. \& Martens, K. (2009) Alternative metrics to measure journal impacts: entering in a 'free market'. Hydrobiologia, 636, 7-10.

Valdecasas, A.G., Castroviejo, S. \& Marcus, L.A. (1990) Reliance on the citation index undermines the study of biodiversity. Nature, 403, 698.

Viets, K.O. (1987) Die Milben des Süßwassers (Hydrachnellae und Halacaridae (part.), Acari). II.: Katalog. Sonderbände des Naturwiss. Vereins Hamburg, 8, 1-1012.

Walter, G., Bloch, S., Hunt, G. \& Fisher, K. (2003) Counting on citations: a flawed way to measure quality. Medical Journal of Australia, 178, 280 - 281.

Wilson, E.O., Carpenter, F.M. \& Brown, W.L. (1967a) The first Mesozoic ants. Science, 157, 1038-1040.

Wilson, E.O., Carpenter, F.M. \& Brown, W.L. (1967b) The first Mesozoic ants, with description of a new subfamily. Psyche 74, 1-19. 